\title{
Evaluation of the effectiveness of Interprofessional Education at Gunma University as the WHO Collaborating Centre: case series
}

\author{
Takatoshi Makino ${ }^{1,2}$, Bumsuk Lee ${ }^{1,2}$, Hiroki Matsui ${ }^{1,2}$, Ena Sato ${ }^{1,2}$, Naoto Noguchi ${ }^{1,2}$, Akinori Kama ${ }^{1,3}$, \\ Hiromitsu Shinozaki ${ }^{1,2}$, Hideomi Watanabe ${ }^{1,4}$ \\ ${ }^{1}$ WHO Collaborating Centre for Research and Training on Interprofessional Education, Gunma University, Maebashi, Japan; ${ }^{2}$ Graduate School of \\ Health Sciences, Gunma University, Maebashi, Japan; ${ }^{3}$ Gunma University Initiative for Advanced Research, Maebashi, Japan; ${ }^{4}$ Faculty of Health \\ Care, Takasaki University of Health and Welfare, Takasaki, Japan \\ Correspondence to: Dr. Takatoshi Makino. Graduate School of Health Sciences, Gunma University, 3-39-22 Showa, Maebashi, Gunma 371-8514, \\ Japan. Email: tmakino@gunma-u.ac.jp.
}

\begin{abstract}
Interprofessional Education (IPE) plays an important role in the acquisition of an attitude for Collaborative Practice (CP) in undergraduate students. IPE offers a possible way to improve collaboration and patient care. While effective IPE programs have been shown to have a number of positive benefits, it is argued that there is only limited evidence of success in measuring the long-term effects of IPE on health care practice and collaboration. The primary aim of this project was to examine the efficacy of IPE at Gunma University. This case is unique in that the provision of IPE for undergraduate students of both medicine and health sciences has fostered the attitudes toward meaningful collaboration. Then there are only two institutions in the world, which specialize in this IPE at Gunma University as well as University of Malawi, as the WHO Collaborating Centre. Gunma University has implemented a comprehensive IPE program, including lecture-style subjects for first-year students and a training-style subject for third-year students since 1997. As an aftermath of IPE intervention, there is realization of IPE may be professional identity and concrete knowledge for patient safety, especially for communication and leadership, commonly in prequalified IPE intervention. Then we strongly suggested that there is a need for in-service IPE in order to sustain attitude and provide a useful CP, which results in good clinical outcome.
\end{abstract}

Keywords: WHO Collaborating Centre; Interprofessional Education (IPE); attitudes; patient safety

Received: 19 May 2021; Accepted: 13 October 2021; Published: 25 June 2022.

doi: $10.21037 /$ jhmhp-21-40

View this article at: https://dx.doi.org/10.21037/jhmhp-21-40

\section{Introduction}

World Health Organization (WHO) (1) has published a report of framework for action on Interprofessional Education (IPE) and interprofessional Collaborative Practice (CP). In the framework, five factors of educator mechanisms support and seven factors of curricular mechanisms which develop and deliver IPE, are identified. IPE plays an important role in the acquisition of an attitude for $\mathrm{CP}$ in undergraduate students (2). IPE offers a possible way to improve collaboration and patient care (3). While effective IPE programs have been shown to have a number of positive benefits, it is argued that there is only limited evidence of success in measuring the long-term effects of IPE on health care practice and collaboration (4). WHO (5) reported the quality of the evidence supporting this recommendation is low, and the strength of the recommendation is conditional. There is an assertion that IPE should start as soon as possible in undergraduate education level, while there is little evidence about the evaluation of such sharing experiences at this level (6). Especially, longitudinal study, as reported by McFadyen et al. [2010] (7), will be necessary.

Since 1997, the Gunma University School of Health Sciences (GUSHS) has implemented a comprehensive IPE program, including lecture-style subjects for first-year students and a training-style subject for third-year students 
$(8,9)$. Since 2015, Gunma University has been promoting a reform of patient safety systems and culture in the university hospital under the leadership of the university president and director of the university hospital. In the series of reforming initiatives, development of an IPE program fostering attitudes of undergraduate students of both medicine and health sciences toward useful collaboration in patient safety was postulated as one of the most urgent challenges in 2018. There is an increased need for IPE in the global health crisis and rapid increasing in COVID-19 (10).

The primary aim of this project was to examine the efficacy of IPE at Gunma University. This case is unique in that the provision of IPE for undergraduate students of both medicine and health sciences has fostered the attitudes toward meaningful collaboration. Then there are only two institutions in the world, which specialize in this IPE at Gunma University as well as University of Malawi, as the WHO Collaborating Centre.

\section{Methods}

\section{Sample}

The participants were recruited from Gunma University Faculty of Medicine which consists of School of Medicine (GUSM, 120 students) and GUSH (160 students). GUSH consists of the department of Nursing (NS, 80 students), Laboratory Sciences (LS, 40 students), Physical Therapy (PT, 20 students) and Occupational Therapy (OT, 20 students). The survey and accompanying cover letter were distributed to students from 1999 to 2018.

\section{Assessment scale \& data analysis}

A questionnaire of 10 items to assess the achievement levels of the program, which was developed independently of other assessment systems published previously, was distributed. A multivariate analysis of variance (MANOVA) model was used, and then factor analysis of the responses was performed with varimax rotation. We examined the professional identity acquisition process model in IPE using structural equation modelling (SEM) (11).

The attitudes toward collaboration for patient safety was evaluated by the modified T-TAQ. The modified T-TAQ is one of the instruments used most frequently in surveys examining the attitudes toward the teamwork for patient safety (12). We used a Japanese version of the questionnaire, a modified T-TAQ, in which four reverse-coded items (items 20, 21, and 24 in the "mutual support" category and item 30 in the "communication" category) were changed to positively-worded items, with reference to the previous literature (13). Mann-Whitney $U$ test was used to analyse dependent variables within individuals for normally distributed data or other data, respectively.

A modified attitudes toward health care teams scale (ATHCTS, 14-item instrument), that removed items containing the word "physician" was created by Curran et al. [2007] (14) to assess attitudes toward health care teams. The scale was subjected to exploratory factor analysis (EFA) to examine the underlying constructs of the survey. The suitability of the correlation matrix was determined by the Kaiser-Meyer-Olkin (KMO) test of sampling adequacy and Bartlett's Test of Sphericity. The initial factor extraction was performed using principal component analysis. Furthermore, to clearly define the structure, an EFA using a varimax rotation was conducted. The regression factor score was computed for the item identified to represent the modified ATHCTS using the varimax rotation method. Since the data were not normally distributed according to the ShapiroWilk test, the Mann-Whitney U test was used to analyse the independent variables.

Data were analysed using IBM SPSS software for Windows, Version 22.0 (Japanese version). A P value of $<0.05$ was considered statistically significant.

\section{Intervention}

GUSHS has developed a curriculum fundamentally based on holistic medicine and CP, as described previously (8). Briefly, there are two lecture-style subjects delivered to first-year students, to develop medical ethics and awareness of patient-centered team care and to understand the history of team care and the practicality of a team approach in a health care/medical care setting. Because GUSH developed the curriculum to learn about IPE for 1st- and 3rd-year undergraduate students to prevent the undesirable effects of highly professional.

The lecture style called "Holistic Medicine/Teamwork Studies" which included mandatory delivery of information on specific topics to the 1st-year students of both GUSM and GUSH. The current IPE Program was mandatory for the 1st-year students of GUSM and GUSH. The objective of the lecture style was to develop the medical ethics and awareness of the patient-centered team care, and to understand the history of team care and facts related to team approaches in the health care/medical care setting. This 
lecture style consisted of 30-hour lessons. The lecture style is provided to students in terms of address the specific needs and challenges, a perspective (public health nurses, clinical laboratory technicians, occupational therapists, physical therapists, nurses), leadership in the $\mathrm{CP}$, roles of $\mathrm{WHO}$ in Human Resources for Health, and so on. According to Barr et al. [2005] (15), if students simply shared lectures without any opportunity for interprofessional interaction or debates, and thus these are considered as multi-professional education (MPE), not IPE.

The training style called "Teamwork Training" is included in mandatory training. This style is a core program of our IPE program, as described previously $(8,9)$. The current IPE Program is mandatory for the 3rd-year students of GUSH and elective with a credit for students of GUSM. A training group consists of ten students; four from NS, two from LS, one each from PT and OT and two from GUSM-proportional to the enrollment capacity of each department. The objective of the training style was to experience of being part of a health care team (the spirit of IPW), to learn about Interprofessional Working (IPW) in clinical practice (the skills of IPW). The students work in groups and undergo a series of activities, including group discussion, clinical training at facilities, general meeting, and reporting a simulated interprofessional training. This training style consisted of 90-hour lessons, including 20-hour lessons (two whole days) in a clinical setting, was conducted. The training style is provided to students to the following; overall guidance (4-hour), promoting of a sense of unity among students in groups (4-hour), group work (24-hour), a kick-off meeting and an overall guidance prior to clinical training (4-hour), clinical training at aboveassigned training facilities (20-hour), group work (20-hour), the debriefing meeting (10-hour), and group work (4-hour).

At least one faculty member is assigned to each group. As all members of group meet only once a week for this training, with the expectation of the clinical training session at facilities, students and faculty use a mailing list for close communication and coordination. During the group work learning process, each group of students develops a clinical training plan closely supported by the faculty as facilitator. Case scenarios common at facilities are developed in advance, and students are expected to deliberate and play their role in their simulation.

\section{Ethics}

All procedures performed in studies involving human participants were in accordance with the Helsinki Declaration (as revised in 2013). This study was approved by The Epidemiologic Research Ethics Committee of Medical and Health Research Involving Human Subjects (Gunma University, Maebashi, Gunma, Japan). Survey responses were kept confidential and names and other identifying information were removed for analysis. Written informed consent was obtained from the participants.

\section{Findings}

As a first step, we evaluated our IPE program from 1997 to 2007 using a questionnaire of 10 items to assess the achievement levels of the program for 3rd-year undergraduate students of GUSH (8). As a result, over $90 \%$ of respondents rated "fully understood" or "understood" in the "importance of teamwork" and revealed four factors; "role and responsibilities", "teamwork and collaboration", "structure and function of training facilities" and "professional identity" as a result of factor analysis. The structural equation modelling technique was utilized to construct the professional identity acquisition process (PIAP) model on the relationships among four factors. The same structure was observed in NS and PT students' PIAP models, but it was not completely the same in LS and OT students' PIAP models. A parallel but not isolated curriculum on expertise unique to the profession, which may help to understand their professional identity in combination with learning the collaboration.

Secondly, the pre-service IPE incorporating TeamSTEPPS has been implemented for undergraduate students and revealed a significant improvement in attitudes toward CP for patient safety. The development of an IPE program fostering attitudes of undergraduate students of both GUSM and GUSH toward useful collaboration in patient safety was postulated as one of the most urgent challenges in 2018. As a result of only 7 out of 30 items showed a significant increase in the modified T-TAQ. There was no significant improvement in students' attitudes in terms of the Communication category implementing face to face IPE.

Finally, a questionnaire survey was distributed to 1st- and 3rd-year undergraduate students of GUSH. As a result of cross-sectional design (9), the overall mean scores significantly declined after learning in the firstyear students, while the scores were significantly improved after learning in the third-year students. As a result of longitudinal design (11), the overall mean scores of "Quality of care delivery" significantly declined after learning in the 
1st-year students, while the scores of "Patient-centered care" significantly improved after learning in the 3rd-year students. In addition to IPE program at a pre-licensure stage, we assessed alumni who have studied in IPE program at a pre-licensure stage whether they maintain a positive attitude toward CP in the clinical settings in a crosssectional study comparing to undergraduate students (16). As a result, the overall mean score of alumni was significantly lower than that of undergraduate students. On the other hand, only "Team efficacy" had a significantly lower regression factor score in alumni than undergraduate students.

\section{Discussion}

Over $90 \%$ of respondents rated "fully understood" or "understood" in the "importance of teamwork". The structural equation modelling technique was utilized to construct the PIAP model on the relationships among four factors. There was no significant improvement in students' attitudes in terms of the Communication category implementing face to face IPE. The overall mean scores of "Quality of care delivery" significantly declined after learning in the 1st-year students, while the scores of "Patient-centered care" significantly improved after learning in the $3 \mathrm{rd}$-year students. IPE initiatives implemented by three different universities demonstrated that one common theme leading to a successful experience among those initiatives included helping students to understand their own professional identity (17). Medical laboratory science educators need to incorporate patient safety concepts into the curricula in the 21 st century and strengthened the importance of communication skills (18). It is, therefore, suggested that the goal of students' realization of IPE may be professional identity and concrete knowledge for patient safety, especially for communication and leadership, commonly in pre-qualified IPE intervention.

The overall mean score of alumni was significantly lower than that of undergraduate students. Only "Team efficacy" had a significantly lower regression factor score in alumni than undergraduate students. New graduates may have a wide range of knowledge at their fingertips, but are often ill-prepared to apply this knowledge with real-world problems (19). The in-service training program is an effective tool with measurable quantitative and qualitative results with positive impact on the quality of care (20). It is, therefore, suggested that there is a need for in-service
IPE in order to sustain attitude and provide a useful CP, which results in good clinical outcome. There is a need for longitudinal approach in the COVID-19 pandemic in order to establish the evidence on online IPE which students learn attitudes toward meaningful collaboration in a team-based setting.

\section{Acknowledgments}

We thank Dr. Tomoyuki Yokoyama for his kind support as Dean, Graduate School of Health Sciences, Gunma University.

Funding: None.

\section{Footnote}

Provenance and Peer Review: This article was commissioned by the editorial office, Fournal of Hospital Management and Health Policy for the series "Interprofessional Education in Asia". The article has undergone external peer review.

Peer Review File: Available at https://jhmhp.amegroups.com/ article/view/10.21037/jhmhp-21-40/prf

Conflicts of Interest: All authors have completed the ICMJE uniform disclosure form (available at https://jhmhp. amegroups.com/article/view/10.21037/jhmhp-21-40/ coif). The series "Interprofessional Education in Asia" as commissioned by the editorial office without any funding or sponsorship. TM served as an unpaid Guest Editor of the series. The authors have no other conflicts of interest to declare.

Ethical Statement: The authors are accountable for all aspects of the work in ensuring that questions related to the accuracy or integrity of any part of the work are appropriately investigated and resolved. All procedures performed in studies involving human participants were in accordance with the Helsinki Declaration (as revised in 2013). This study was approved by The Epidemiologic Research Ethics Committee of Medical and Health Research Involving Human Subjects (Gunma University, Maebashi, Gunma, Japan). Survey responses were kept confidential and names and other identifying information were removed for analysis. Written informed consent was obtained from the participants.

Open Access Statement: This is an Open Access article 
distributed in accordance with the Creative Commons Attribution-NonCommercial-NoDerivs 4.0 International License (CC BY-NC-ND 4.0), which permits the noncommercial replication and distribution of the article with the strict proviso that no changes or edits are made and the original work is properly cited (including links to both the formal publication through the relevant DOI and the license). See: https://creativecommons.org/licenses/by-nc-nd/4.0/.

\section{References}

1. World Health Organization. Framework for action on interprofessional education and collaborative practice. Geneva: WHO, 2010.

2. Coster S, Norman I, Murrells T, et al. Interprofessional attitudes amongst undergraduate students in the health professions: a longitudinal questionnaire survey. Int J Nurs Stud 2008;45:1667-81.

3. Reeves S, Perrier L, Goldman J, et al. Interprofessional education: effects on professional practice and healthcare outcomes (update). Cochrane Database Syst Rev 2013;(3):CD002213.

4. Lê Q, Spencer J, Whelan J. Development of a tool to evaluate health science students' experiences of an interprofessional education (IPE) programme. Ann Acad Med Singap 2008;37:1027-33.

5. World Health Organization. WHO Education Guidelines 2013: Transforming and scaling up health professionals' education and training. Geneva: WHO, 2013.

6. Hoffman SJ, Harnish D. The merit of mandatory interprofessional education for pre-health professional students. Med Teach 2007;29:e235-42.

7. McFadyen AK, Webster VS, Maclaren WM, et al. Interprofessional attitudes and perceptions: Results from a longitudinal controlled trial of pre-registration health and social care students in Scotland. J Interprof Care 2010;24:549-64.

8. Ogawara H, Hayashi T, Asakawa Y, et al. Systematic inclusion of mandatory interprofessional education in health professions curricula at Gunma University: a report of student self-assessment in a nine-year implementation. Hum Resour Health 2009;7:60.

9. Hayashi T, Shinozaki H, Makino T, et al. Changes in attitudes toward interprofessional health care teams and education in the first- and third-year undergraduate students. J Interprof Care 2012;26:100-7.
10. Singh J, Matthees B. Facilitating Interprofessional Education in an Online Environment during the COVID-19 Pandemic: A Mixed Method Study. Healthcare (Basel) 2021;9:567.

11. Kururi N, Tozato F, Lee B, et al. Professional identity acquisition process model in interprofessional education using structural equation modelling: 10-year initiative survey. J Interprof Care 2016;30:175-83.

12. Baker DP, Amodeo AM, Krokos KJ, et al. Assessing teamwork attitudes in healthcare: development of the TeamSTEPPS teamwork attitudes questionnaire. Qual Saf Health Care 2010;19:e49.

13. Ochiai K., Kaito K. The Guide of Team STEPPS for Japanese. Tokyo: Medical View Co., 2012:12-49.

14. Curran VR, Sharpe D, Forristall J. Attitudes of health sciences faculty members towards interprofessional teamwork and education. Med Educ 2007;41:892-6.

15. Barr H, Koppel I, Reeves S, et al. Effective interprofessional education: Argument, assumption and evidence. Oxford: Blackwell Publishing, 2005.

16. Makino T, Shinozaki H, Hayashi K, et al. Attitudes toward interprofessional healthcare teams: a comparison between undergraduate students and alumni. J Interprof Care 2013;27:261-8.

17. Bridges DR, Davidson RA, Odegard PS, et al. Interprofessional collaboration: three best practice models of interprofessional education. Med Educ Online 2011.

18. Morris S, Otto CN, Golemboski K. Improving patient safety and healthcare quality in the 21 st century-competencies required of future medical laboratory science practitioners. Clin Lab Sci 2013;26:200-4.

19. Blouin RA, Joyner PU, Pollack GM. Preparing for a Renaissance in pharmacy education: the need, opportunity, and capacity for change. Am J Pharm Educ 2008;72:42.

20. Blakey H, Blanshard E, Cole H, et al. Are medical students socially exclusive? A comparison with economics students. Med Educ 2008;42:1088-91.

doi: $10.21037 /$ /hmhp-21-40

Cite this article as: Makino T, Lee B, Matsui H, Sato E, Noguchi N, Kama A, Shinozaki H, Watanabe H. Evaluation of the effectiveness of Interprofessional Education at Gunma University as the WHO Collaborating Centre: case series. J Hosp Manag Health Policy 2022;6:19. 